Case Report

\title{
Tongue Osseous Choristoma in an 11-Year-Old Female: A Case Report and Literature Review Focusing on Pediatric Cases
}

\author{
Satomi Arimoto $\mathbb{D}^{1},{ }^{1}$ Manabu Shigeoka $\mathbb{D}^{2},{ }^{2}$ and Masaya Akashi $\mathbb{D}^{1}$ \\ ${ }^{1}$ Division of Oral and Maxillofacial Surgery, Department of Surgery Related, Kobe University Graduate School of Medicine, \\ Kobe, Japan \\ ${ }^{2}$ Division of Pathology, Department of Pathology, Kobe University Graduate School of Medicine, Kobe, Japan
}

Correspondence should be addressed to Manabu Shigeoka; shigeokamanabu@gmail.com

Received 12 May 2021; Revised 2 September 2021; Accepted 28 September 2021; Published 13 October 2021

Academic Editor: Eugenio Maiorano

Copyright (c) 2021 Satomi Arimoto et al. This is an open access article distributed under the Creative Commons Attribution License, which permits unrestricted use, distribution, and reproduction in any medium, provided the original work is properly cited.

\begin{abstract}
Osseous choristoma is an uncommon benign lesion characterized by the presence of ectopic mature bone within soft tissue. In most cases, these lesions occur on the dorsum of the tongue in patients in their third and fourth decades of life. This article describes a case of lingual osseous choristoma in a pediatric patient. An eleven-year-old girl with a lingual mass was referred to our hospital from a dental clinic. Total excisional biopsy and histological examination were performed, and osseous choristoma was diagnosed. The postoperative course was uneventful with no signs of recurrence during the 12 months after surgery. Moreover, a literature review focusing on pediatric cases with lingual osseous choristoma was performed to know the etiology, clinicopathological characteristics, and course of treatment of the lesion.
\end{abstract}

\section{Introduction}

Choristoma is defined as a tumor-like lesion that is composed of normal tissue in an abnormal location. In 1971, Krolls et al. proposed the term "osseous choristoma" for soft tissue osteoma in the head and neck region [1], and this term has been widely used since. Osseous choristoma is a rare benign lesion characterized by the presence of ectopic mature bone within soft tissue and is more often composed of bone and cartilage [2]. Lingual osseous choristoma is a rather rare entity with less than 100 reported cases in the literature [3]. The pathogenesis of these lesions has remained unexplained [4]. Most cases of intraoral osseous choristoma occur in the tongue (especially its dorsal surface) [2]. Most patients with lingual osseous choristoma are women in their third or fourth decade of life [2]. These lesions are considered self-limiting in their growth. On oral examination, they frequently appear as painless, pedunculated nodules on the tongue that are firm on palpation [5]. Lingual masses can include osseous choristoma or other lesions such as fibroma, papilloma, pyogenic granulomas, squamous cell carcinomas, or hemangiomas [6]. Even though some patients may be asymptomatic, a wide array of symptoms, including gagging, dysphagia, foreign body sensation, throat irritation, discomfort, and pain, have been reported [7]. Physical examination and diagnostic imaging may assist in identifying the mass; however, a definitive diagnosis requires histologic examination. The microscopic features of osseous choristoma include a well-circumscribed mass of viable lamellar bone with haversian canals, a well-developed mass of mature viable cartilage, or a mixture of bone and cartilage surrounded by dense fibrous connective tissue with thin stratified squamous epithelium. Only a few pediatric patients with lingual osseous choristoma have been reported so far [4]. On the other hand, no previous reports of lingual osseous choristoma have highlighted the features of pediatric patients. This report is aimed at presenting another case of lingual osseous choristoma in a pediatric patient and at reviewing the relevant literature focusing on pediatric cases. A thorough literature search was carried out on PubMed and Google Scholar 
using search terms like "osseous choristoma," "soft tissue osteoma," and "lingual" or "tongue."

\section{Case Presentation}

An 11-year-old Japanese girl told her dentist about a mass in her tongue and was referred to our hospital. She had noticed an asymptomatic nodule at the dorsum of the tongue. However, the fear of being diagnosed with a malignant condition prevented her from consulting a doctor, at least for a while. She had been aware of its existence for 2-3 years before her first visit. She was diagnosed with pneumonia at the age of one year but had no other remarkable medical history. She was not on any long-term medications. Her clinical examination revealed a pedunculated mass covered with normal mucosa in the tongue's posterior portion (Figure 1). The lesion was approximately $7 \mathrm{~mm}$ in diameter. Although the lesion was asymptomatic and clinically diagnosed as a benign soft tissue tumor, the patient and her parents were concerned about the possibility of malignancy. A total excisional biopsy was thus performed under general anesthesia. Our patient's lesion was composed of mature bone tissue surrounded by fibrous stroma and lined by normal squamous epithelium. This lesion was regarded as ectopic bone tissue localized far away from the maxilla-mandibular bone, and the histological diagnosis of osseous choristoma was made microscopically (Figure 2). Since the pathological specimen's preparation required the resected sample's decalcification, the final diagnosis could not be determined until $\sim 30$ days postsurgery, when the histological diagnosis was revealed as osseous choristoma. This waiting period was difficult for the patient and her family. Twelve months postoperatively, no symptoms of recurrence have been observed.

\section{Discussion}

Lingual osseous choristoma is rare among pediatric patients. In this manuscript, we present another pediatric case of lingual osseous choristoma and review the relevant literature.

In Japan, most children attend pediatric clinics until the age of $\sim 12$ years. Thus, we focused on patients below the age of 13 years with osseous choristoma in our literature search. To our knowledge, in the literature, 62 cases have been described on patients above the age of 13 years (Table 1) $[1,3,6,8-45]$. On the other hand, 16 cases have been described in children below the age of 13 years (Table 2) $[1,2,4,6,31,44,46-55]$. On the other hand, only one pediatric case with intraoral nonlingual osseous choristoma was found [34]. We could not detect the crucial differences in clinicopathological features between pediatric cases and the others.

We summarized the characteristics of the 17 cases with pediatric lingual osseous choristoma including our case in Table 2. Most pediatric patients with lingual osseous choristoma are females ( 4 males, 13 females). Although these findings are consistent with previous reports $[4,54]$, we could not identify the reason for the sexual predisposition. The patients' ages ranged from 5 years to 11 years (mean 9.3 years, median 10 years using Excel function). It has been

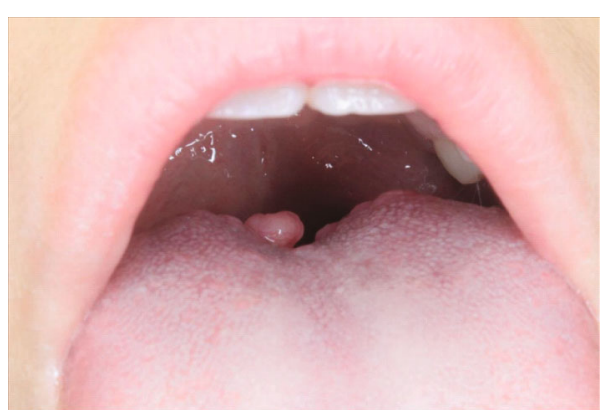

FIgURE 1: Intraoral clinical findings of the 11-year-old female patient. A mass approx. $7 \mathrm{~mm}$ in dia. was observed on the posterior dorsum of the tongue. This lesion with no symptoms was diagnosed clinically as a fibroma.

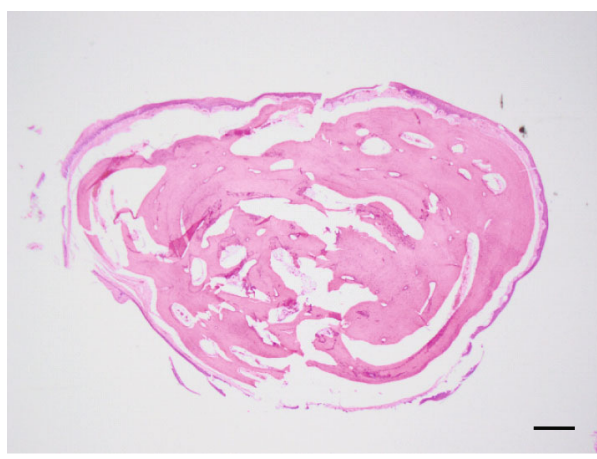

(a)

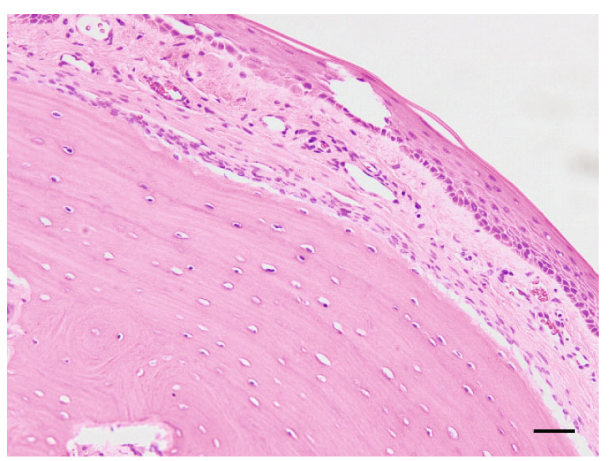

(b)

FIgure 2: Histological findings. (a) Low-power image. A nodule consisting of matured bone surrounded by normal fibrous tissue was observed. Squamous epithelium that covered them is seen. Few inflammatory cells infiltrated into the lesion. Scale bar: $500 \mu \mathrm{m}$. (b) High-power image. Several osteocytes are observed in the matured bone. The squamous epithelium has no atypia. Scale bar: $50 \mu \mathrm{m}$.

demonstrated that most of the lesions develop as symptomless $3-50 \mathrm{~mm}$ masses located in the tongue's posterior third in the area of circumvallate papillae or close to the foramen caecum $[4,54]$. The findings reported in our manuscript are in line with previous reports. It has been reported that dysphagia, a gapping sensation, pain, vomiting reflex, and nausea are the most frequent symptoms of this condition [4]. Five patients had a history of these symptoms (29.4\%). Moreover, a systematic review reported a correlation 


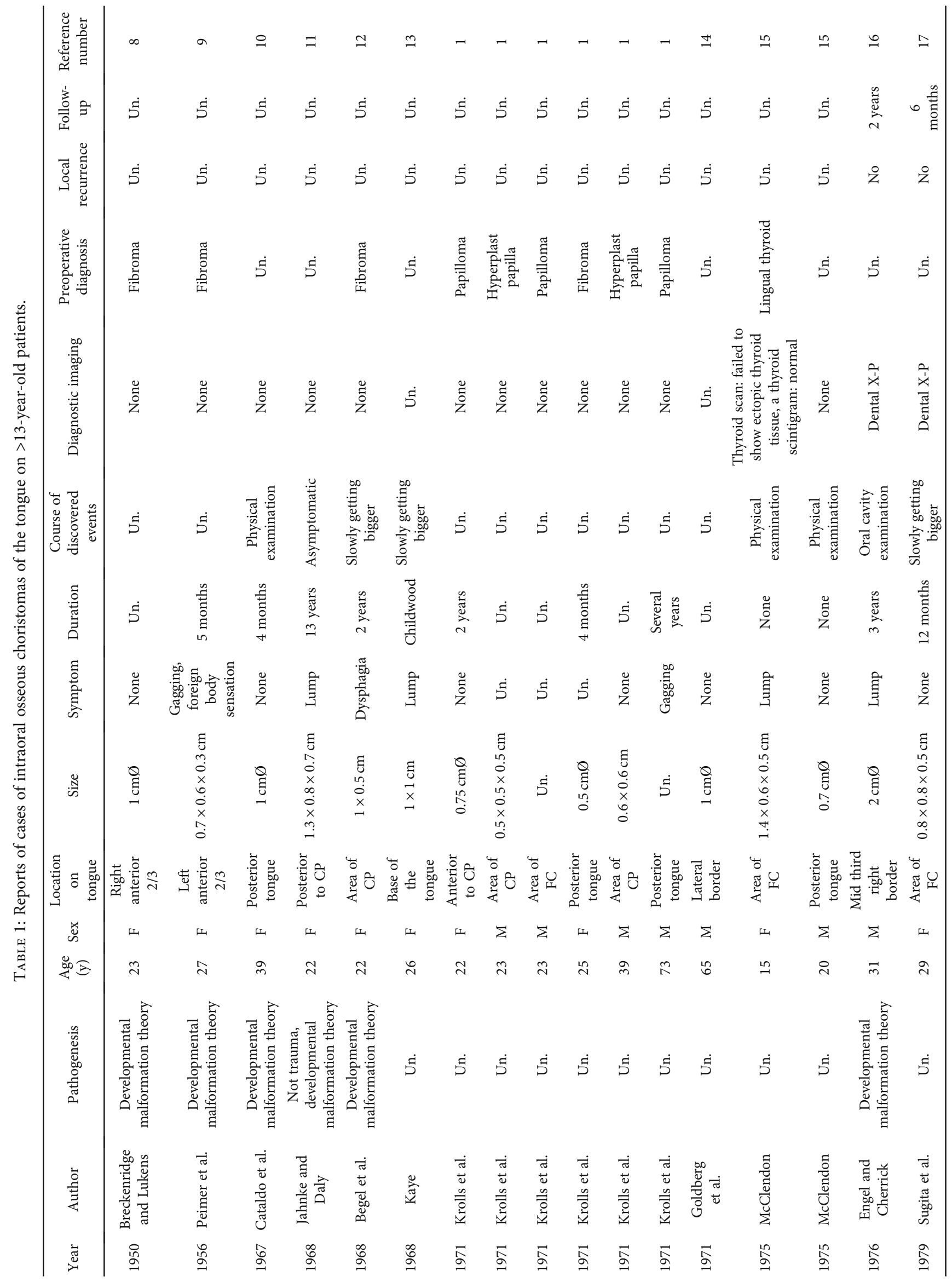




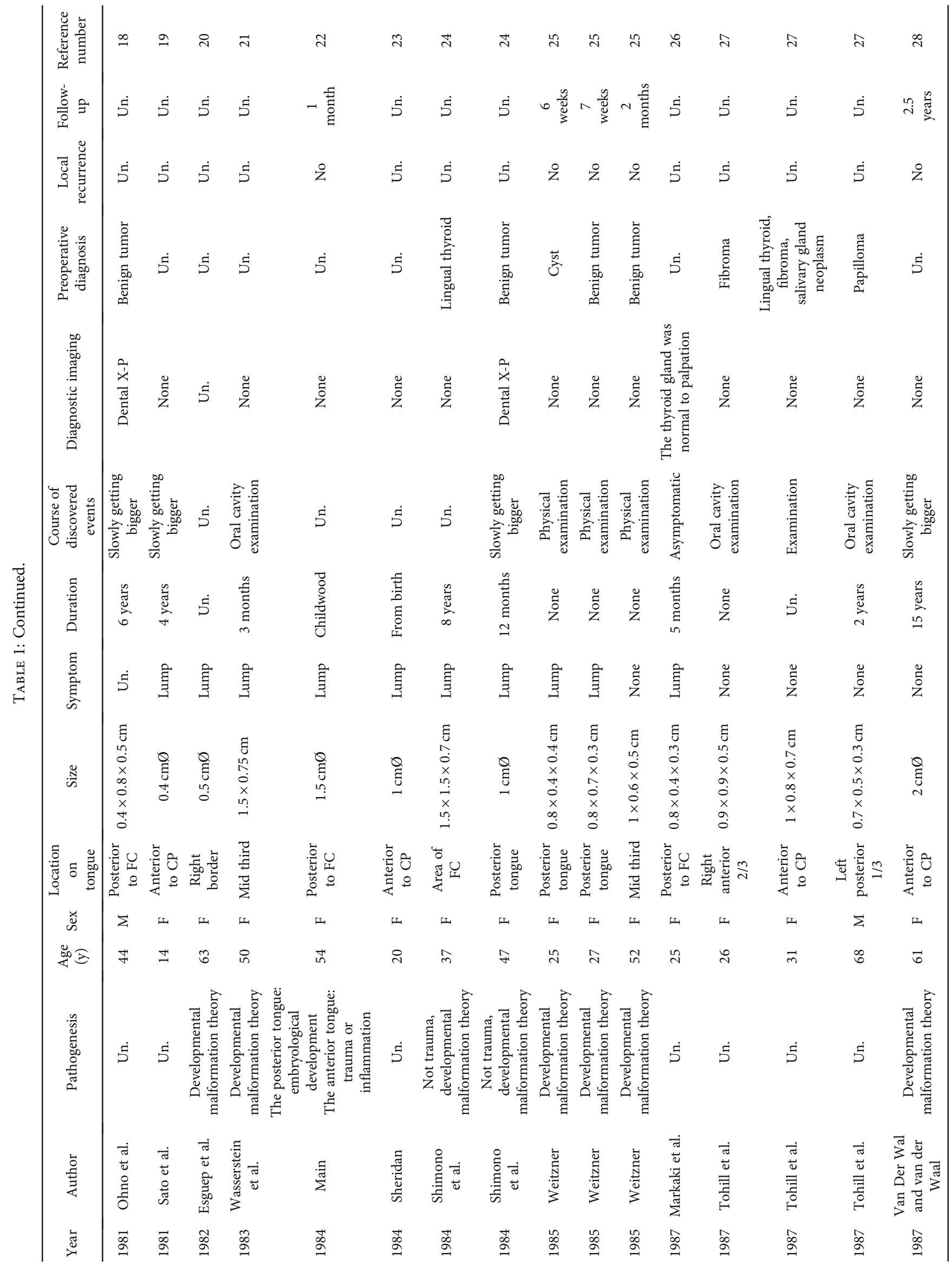




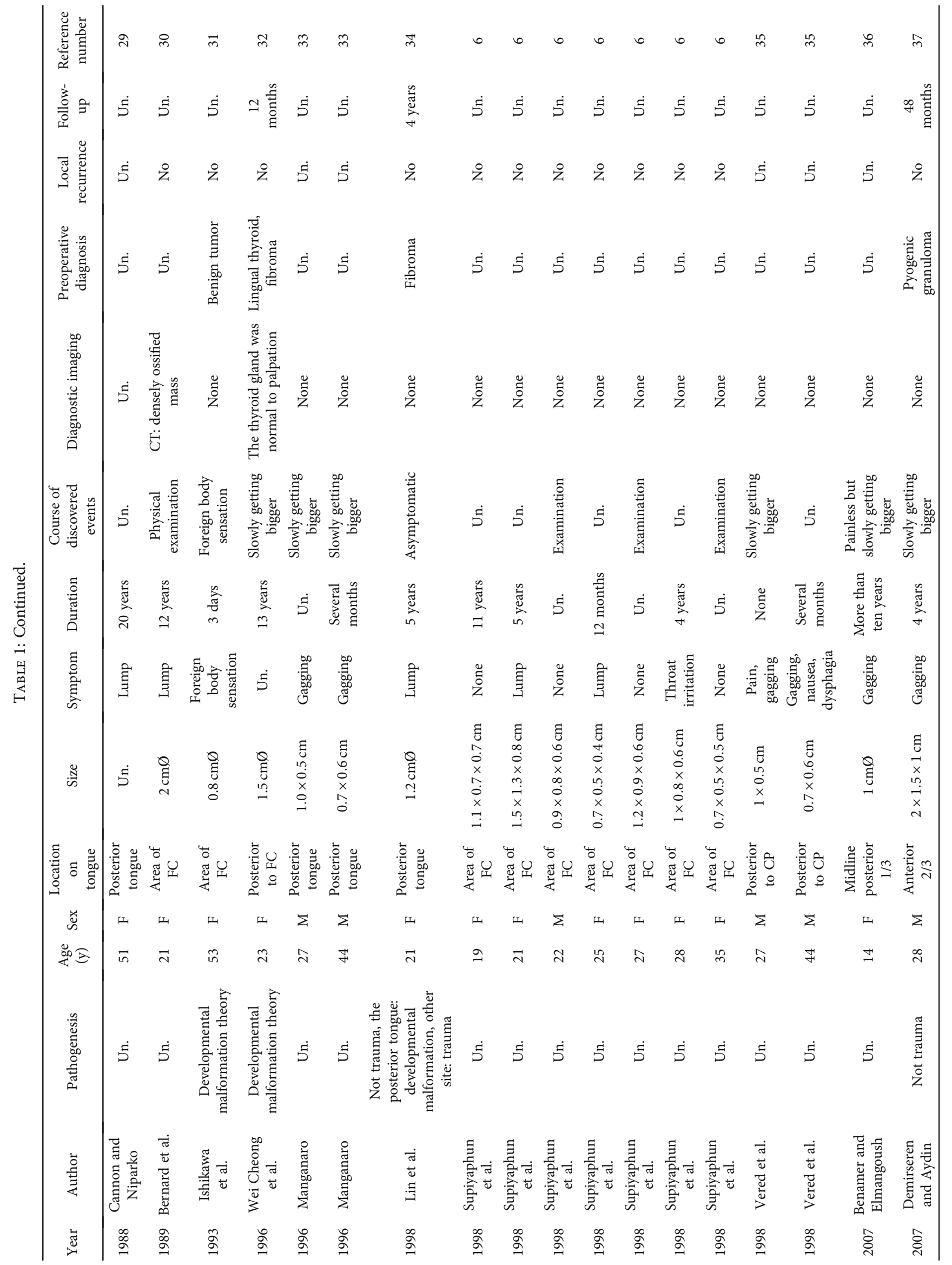




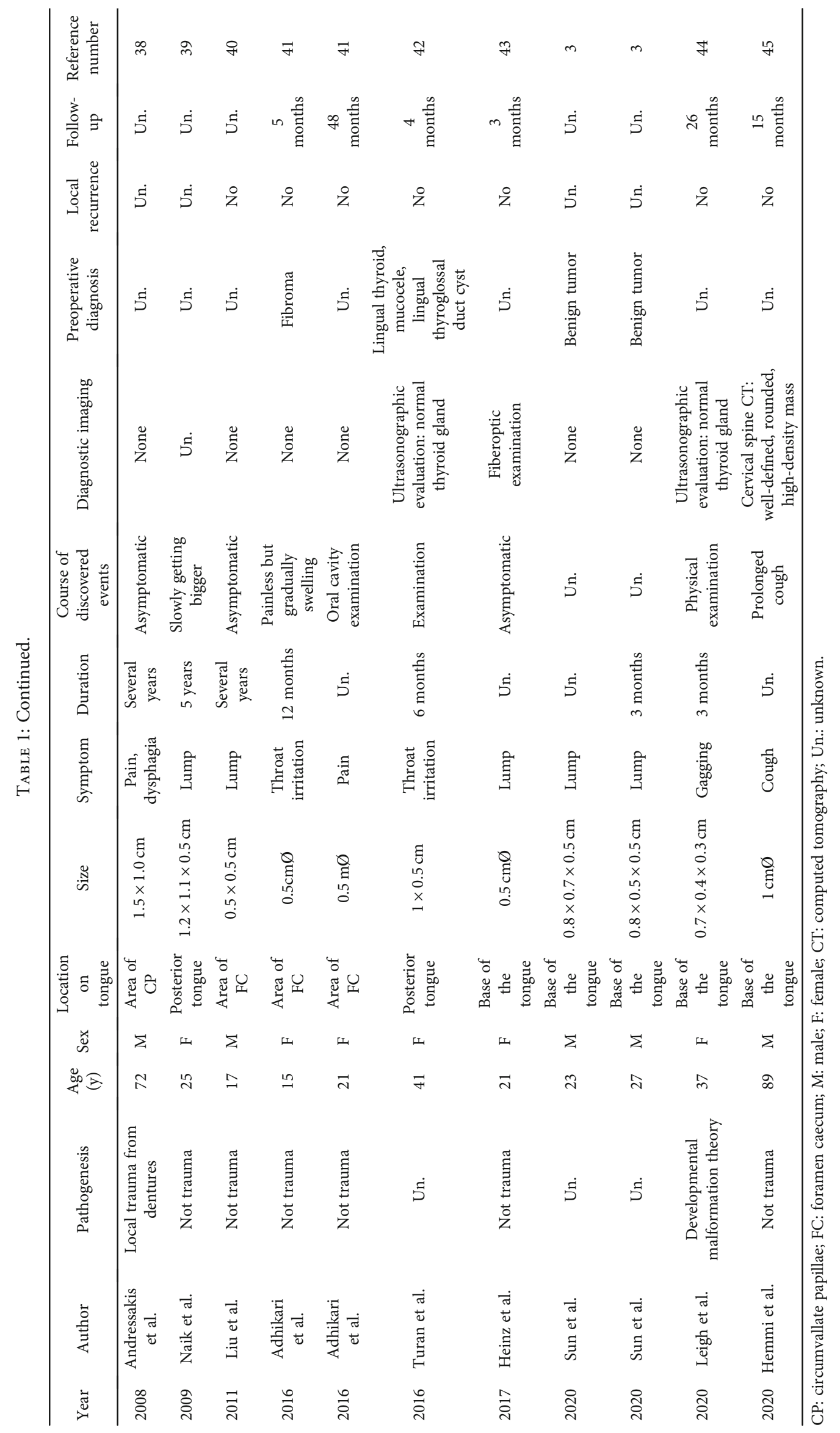




\begin{tabular}{|c|c|c|c|c|c|c|c|c|c|c|c|c|c|}
\hline 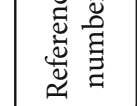 & $\mathscr{l}$ & - & - & f & $\stackrel{\infty}{+}$ & Fे & $\vec{m}$ & in & 0 & $\vec{n}$ & $r$ & กิ & $\hat{n}$ \\
\hline 产 & $\dot{5}$ & म் & $\dot{5}$ & मे & $\dot{5}$ & $\dot{5}$ & $\dot{5}$ & $\dot{5}$ & $\dot{5}$ & $\dot{5}$ & 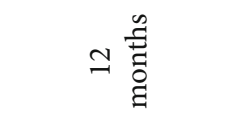 & 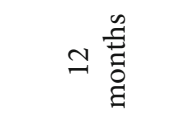 & $\dot{5}$ \\
\hline 芯 & $\dot{5}$ & $\dot{5}$ & $\dot{5}$ & $\dot{5}$ & $\dot{5}$ & $\dot{5}$ & $\stackrel{\circ}{z}$ & s் & $\stackrel{\circ}{z}$ & $\dot{5}$ & $\stackrel{\circ}{z}$ & $\stackrel{\circ}{z}$ & $\dot{5}$ \\
\hline 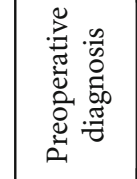 & $\dot{5}$ & 营 & 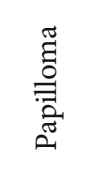 & s. & 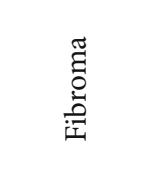 & $\dot{5}$ & 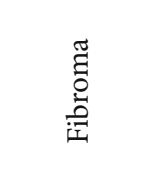 & $\dot{5}$ & $\dot{5}$ & $\dot{5}$ & $\dot{5}$ & 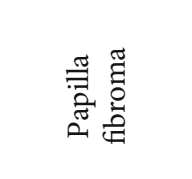 & 5் \\
\hline 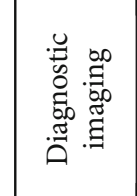 & 气̆ & $\stackrel{\tilde{\Xi}}{z}$ & $\stackrel{\Xi}{\tilde{z}}$ & $\begin{array}{l}\text { Z̆ } \\
\text { z }\end{array}$ & Zั & $\dot{5}$ & $\stackrel{\tilde{z}}{z}$ & 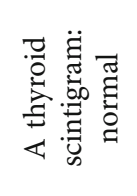 & ż & $\dot{5}$ & 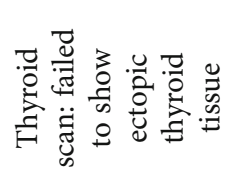 & 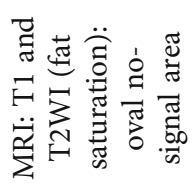 & \\
\hline 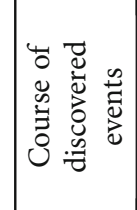 & 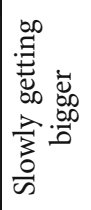 & 5 & $\dot{5}$ & 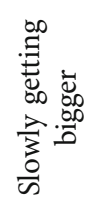 & 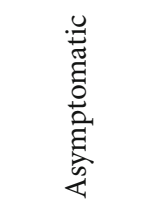 & $\dot{5}$ & 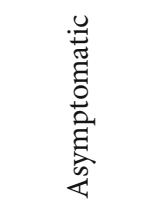 & 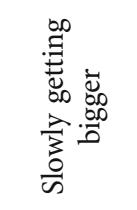 & 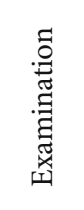 & म் & 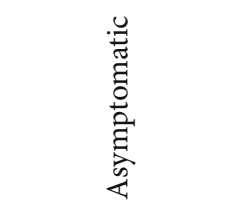 & 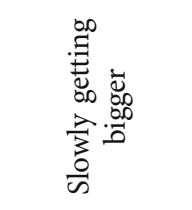 & 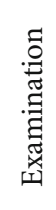 \\
\hline 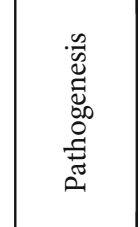 & s் & $\dot{5}$ & sं & $\dot{5}$ & 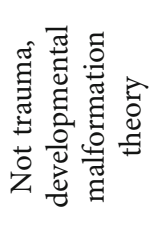 & 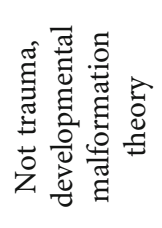 & 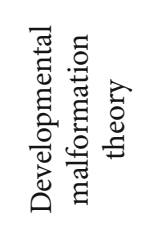 & 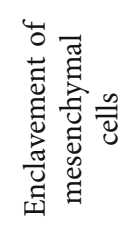 & $\dot{5}$ & s் & 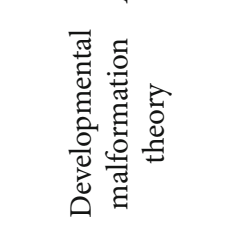 & 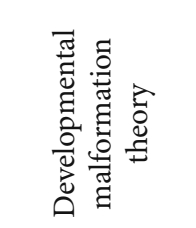 & Б் \\
\hline $\begin{array}{l}\stackrel{\Xi}{\Xi} \\
\stackrel{\Xi}{\Xi} \\
0\end{array}$ & Бٔ & 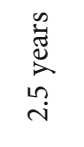 & 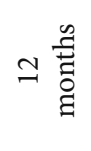 & 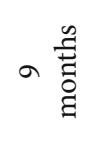 & 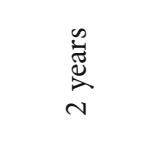 & $\dot{5}$ & 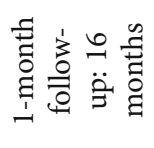 & 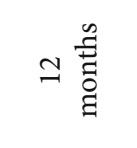 & म & $\dot{5}$ & 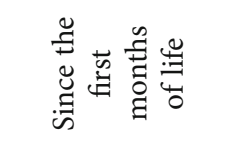 & 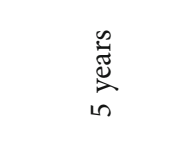 & Бं \\
\hline 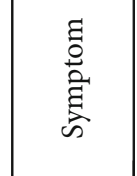 & 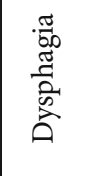 & $\begin{array}{l}\infty \\
.0 \\
0 \\
0 \\
0\end{array}$ & $\dot{5}$ & 志 & 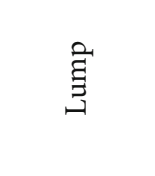 & 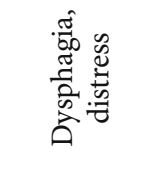 & 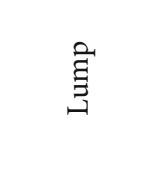 & 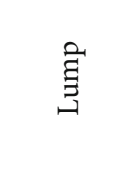 & 气̆ & 冚 & 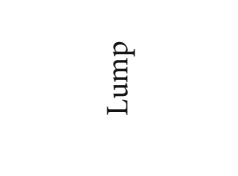 & 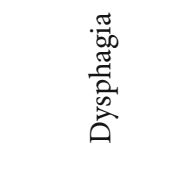 & \\
\hline$\stackrel{\tilde{N}}{\tilde{\omega}}$ & $\begin{array}{l}\text { Qै } \\
\text { हु } \\
\text { n }\end{array}$ & $\dot{5}$ & $\begin{array}{l}\text { Q } \\
\text { हु } \\
\text { v }\end{array}$ & $\begin{array}{l}\overrightarrow{\tilde{N}} \\
\text { p } \\
\tilde{J} \\
\tilde{D}\end{array}$ & $\begin{array}{l}\tilde{y} \\
0 \\
n \\
0 \\
x \\
10 \\
0 \\
0 \\
x \\
0 \\
0 \\
0\end{array}$ & $\begin{array}{l}\tilde{g} \\
+ \\
\dot{x} \\
\text { in }\end{array}$ & $\begin{array}{l}0 \\
\text { है } \\
\infty \\
0 \\
\uparrow \\
\uparrow \\
0\end{array}$ & है & $\begin{array}{l}E \\
\tilde{y} \\
0 ? \\
0 \\
x \\
0 \\
0 \\
0 \\
x \\
1 \\
0\end{array}$ & $\dot{5}$ & $\begin{array}{l}Q \\
\text { है } \\
-1\end{array}$ & $\begin{array}{l}\tilde{J} \\
0 \\
0 \\
\times \\
\times \\
\infty \\
0\end{array}$ & $\begin{array}{l}\text { E } \\
\infty \\
0 \\
\dot{0} \\
x \\
0 \\
\dot{0} \\
x \\
-1 \\
-1\end{array}$ \\
\hline 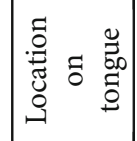 & 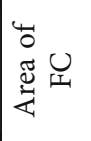 & 岁 & 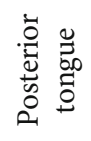 & 岁 & 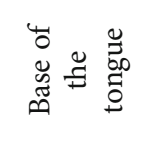 & 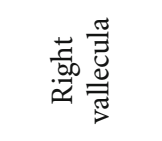 & 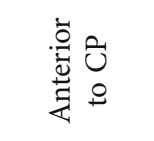 & 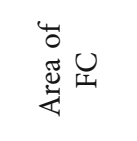 & 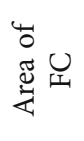 & 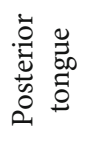 & 岁 & 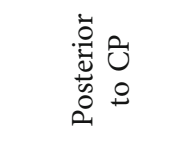 & \\
\hline 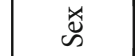 & 山 & 山 & $\omega$ & 山 & 山 & $山$ & 山 & 山 & 山 & 山 & $\omega$ & $\Sigma$ & $\Sigma$ \\
\hline 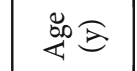 & $\exists$ & $a$ & $=$ & $\infty$ & in & $\infty$ & in & $=$ & $a$ & $=$ & 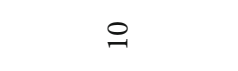 & $=$ & $=$ \\
\hline 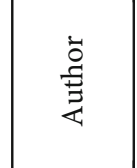 & 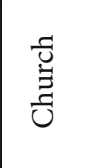 & 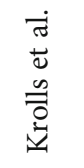 & $\begin{array}{l}\dot{0} \\
\tilde{0} \\
0 \\
0 \\
0 \\
0 \\
0\end{array}$ & 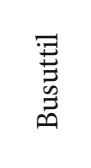 & 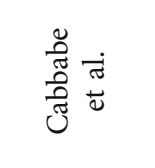 & 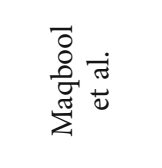 & 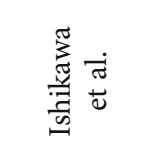 & 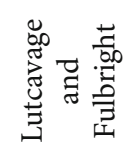 & 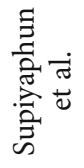 & 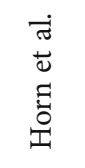 & $\begin{array}{l}\vec{\pi} \\
\tilde{0} \\
\ddot{\Xi} \\
0 \\
0\end{array}$ & 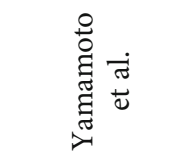 & \\
\hline 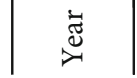 & $\begin{array}{l}\text { ఫે } \\
\text { ऽ }\end{array}$ & 총 & 종 & 余 & $\begin{array}{l}\stackrel{\circ}{\circ} \\
\stackrel{-}{-}\end{array}$ & $\sigma$ & ڤ̆ & & $\stackrel{\infty}{\stackrel{\circ}{\sigma}}$ & 总 & $\underset{d}{\stackrel{\pi}{c}}$ & 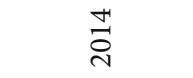 & $\stackrel{n}{\stackrel{\sim}{\sim}}$ \\
\hline
\end{tabular}




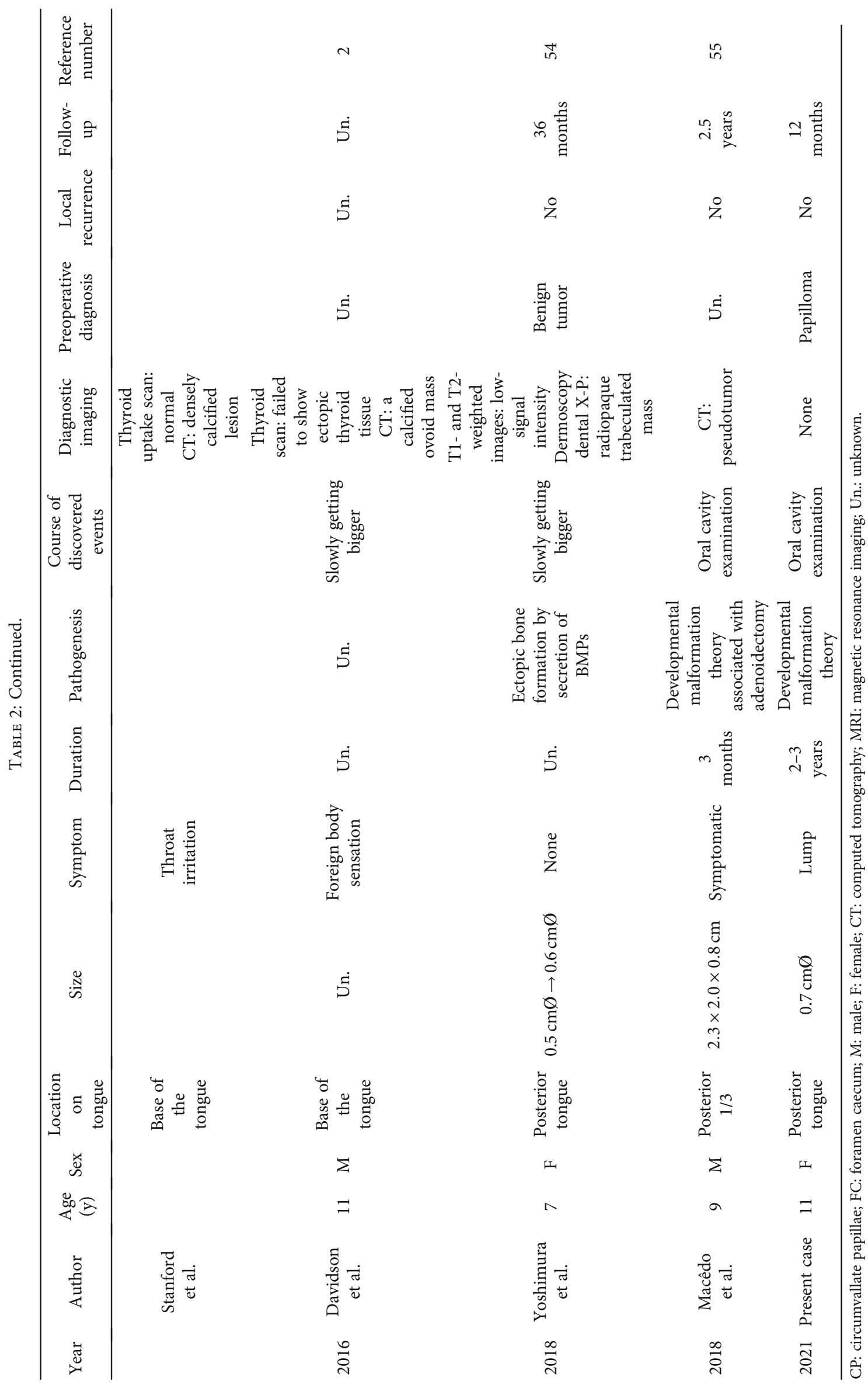


between these symptoms and lesion size [4]; however, another review concluded that there was no correlation between them [6]. Hemmi et al. reported an adult case of lingual osseous choristoma with prolonged cough. They concluded that the cough was due to gastroesophageal reflux disease. Regarding the correlation in pediatric cases, we could not conclude from only 5 cases $(29.4 \%)$. To resolve this discordance, it is necessary to recruit more cases [45]. The follow-up period ranged from one year to three years. No evidence of spontaneous loss or malignant transformation has been reported. No case of pediatric lingual osseous choristoma showed any sign of recurrence [7], while only two recurrent nonpediatric cases of the buccal mucosa lesion were reported $[56,57]$. Long et al. reported that the recurrent lesion could have arisen as a result of the surgical trauma caused by the removal of the original lesion; however, this theory could not explain the occurrence of the original lesion because the patient denied any history of trauma [56]. Besides, according to Dalkiz et al., lesions do not recur once excised and the recurrent lesion might have been caused by a new fibrotic region that underwent ossification an uncalcified lesion that subsequently ossified [57]. Although the mechanisms of recurrence remain uncertain, cases of extralingual lesions should have a longer follow-up period. Our patient's clinical findings were consistent with previous reports. Taking into account the fact that our patient was referred from a private dental clinic, not only head and neck clinicians but also dentists should be familiar with the clinical features of this disease.

The pathogenesis of osseous choristoma is not yet known, a "developmental malformation hypothesis" and a "chronic trauma-associated reactive hypothesis" were proposed $[4,16,41,54,58]$. The involvement of systemic diseases has not been reported. With respect to the former, the lesion arises at the line of fusion of the first and third brachial arches between the anterior two-thirds and posterior one-third of the tongue [41]. Additionally, some researchers indicated that the lingual thyroid remnant ossification is associated with developmental malformation theory due to it occurring at the posterior tongue near the foramen cecum $[12,30]$. However, no thyroid tissue was observed in the current case. With respect to the latter, on the other hand, the osseous lesion on the tongue appeared due to a reactive or posttraumatic center of ossification [41]. There were no previous cases that support the reactive hypothesis. In the current case, there was no evidence of irritational factors. Moreover, our patient's microscopic findings showed no reactive epithelial change, including acanthosis and cell atypia, and little inflammatory cell infiltration and fibrosis were observed. From these clinicopathological features, the "developmental malformation hypothesis" seems likely to apply in this case.

Finally, it cannot be overlooked that the 30-day waiting period until the histological diagnosis of the patient's lesion was stressful for the patient and her family. Although the reason for the long waiting time was the need to decalcify the bone tissue, the psychological care we provided was insufficient. It was speculated that the information provided by imaging modalities can help reduce patients' anxiety.
Diagnostic imaging was conducted in five pediatric cases. Given that no attending surgeons considered the possibility of an osseous choristoma, we did not conduct any imaging examination in this case. An earlier study reported computed tomography (CT) images are useful for the radiological diagnosis of lingual osseous choristoma [45]. Also, Yoshimura et al. reported the usefulness of not only radiographic examination for the surgical specimen. Additionally, they proposed developing a miniaturized, flexible dermoscopy that enabled the detailed examination of the whole oral cavity [54]. However, it is difficult for children to follow instructions when undergoing a CT scan, which often leads to motion artifacts [45]. It is also important to consider the effect of radiation exposure in pediatric patients. Furthermore, a case that occurred in the choroid was diagnosed using ultrasonography [59]; however, there are no reports of ultrasonography being used to diagnose lingual osseous choristoma as it might be difficult to use ultrasonography on the base of the tongue. Therefore, radiographic examination of the surgical specimen might be the most useful tool in the diagnosis of lingual osseous choristoma in pediatric patients.

In conclusion, we presented a pediatric case of lingual osseous choristoma and conducted a review of the literature to identify the characteristics of pediatric cases of the lesion.

\section{Data Availability}

The data used to support the findings of this study are available from the corresponding author upon request.

\section{Conflicts of Interest}

The authors declare that there is no conflict of interest regarding the publication of this article.

\section{Authors' Contributions}

S.A. was responsible for the manuscript drafting, literature search, and collection of clinical records. M.S. was responsible for the histological evaluation and the revision of the manuscript. M.A. supervised the work. All authors reviewed and accepted the final version of the manuscript.

\section{Acknowledgments}

We thank Prof. Tomoo Ito for the valuable discussions and histopathological suggestions and all technicians of the Division of Diagnostic Pathology, Department of Pathology, Kobe University, for the excellent technical assistance.

\section{References}

[1] S. O. Krolls, J. R. Jacoway, and W. N. Alexander, "Osseous choristomas (osteomas) of intraoral soft tissues," Oral Surgery, Oral Medicine, and Oral Pathology, vol. 32, no. 4, pp. 588-595, 1971.

[2] S. Davidson, M. Steiner, and M. Nowicki, "Lingual osseous choristoma," The Journal of Pediatrics, vol. 168, pp. 247247.e1, 2016. 
[3] H. A. Sun, W. T. Lee, and H. J. Hsu, "Lingual osteoma-a case report and literature review," Ear, Nose, \& Throat Journal, no. article 145561320977469, 2020.

[4] E. Gorini, M. Mullace, L. Migliorini, and E. Mevio, "Osseous choristoma of the tongue: a review of etiopathogenesis," Case Reports in Otolaryngology, vol. 2014, Article ID 373104, 5 pages, 2014.

[5] J. E. Bouquot and M. S. H. Nikai, "Lesions of oral cavity," in Diagnostic surgical pathology of the head and neck, D. Gnepp, Ed., Saunders Elsevier, Amstedam, 2nd ed edition, 2009.

[6] P. Supiyaphun, P. Sampatanakul, V. Kerekhanjanarong, P. Chawakitchareon, and V. Sastarasadhit, "Lingual osseous choristoma: a study of eight cases and review of the literature," Ear, Nose, \& Throat Journal, vol. 77, no. 4, pp. 316-325, 1998.

[7] Z. J. Shareef, S. J. Shareef, C. C. Kerndt, A. Aughenbaugh, and A. Di Ponio, "Lingual osseous choristoma: a systematic review of lesion presentation, histology, and morphology," Spartan Medical Research Journal, vol. 5, no. 2, p. 17543, 2020.

[8] R. L. Breckenridge and R. M. Lukens, "Osteoma of the tongue," Archives of Otolaryngology, vol. 52, no. 1, pp. 19-24, 1950.

[9] D. H. Dreizin, Y. Masugi, and R. Peimer, "Osteoma of the tongue," A.M.A. Archives of Otolaryngology, vol. 64, no. 2, pp. 148-150, 1956.

[10] E. Cataldo, G. Shklar, and I. Meyer, "Osteoma of the tongue," Archives of Otolaryngology, vol. 85, no. 2, pp. 202-206, 1967.

[11] V. Jahnke and J. F. Daly, "Osteoma of the tongue," The Journal of Laryngology and Otology, vol. 82, no. 3, pp. 273-275, 1968.

[12] H. Begel, H. Wilson, G. Stratigos, and R. F. Zambito, "Osteoma of the tongue: report of case," Journal of Oral Surgery, vol. 26, no. 10, pp. 662-664, 1968.

[13] W. H. Kaye, "Osteoma of the tongue," The Journal of Laryngology and Otology, vol. 82, no. 3, pp. 269-271, 1968.

[14] A. F. Goldberg, D. F. Skuble, and R. J. Latronica, "Osteoma of the tongue: report of case," Journal of Oral Surgery, vol. 28, no. 6, p. $457,1970$.

[15] E. H. McClendon, "Lingual osseous choristoma: Report of two cases," Oral Surgery, Oral Medicine, and Oral Pathology, vol. 39, no. 1, pp. 39-44, 1975.

[16] P. Engel and H. M. Cherrick, "Extraosseous osteomas of the tongue," Journal of Oral Medicine, vol. 31, no. 4, pp. 99-103, 1976.

[17] H. Sugita, E. Yamamoto, H. Sunakawa, T. Matsubara, I. Furuta, and G. I. Kohama, "Lingual osseous choristoma: report of a case," Japanese Journal of Oral and Maxillofacial Surgery, vol. 25, no. 6, pp. 1417-1421, 1979.

[18] T. Ohno, H. Y. E. Morii, A. Takahashi et al., "Osseous choristoma situated on the dorusum of the root of the tongue: report of a case," Japanese Journal of Oral and Maxillofacial Surgery, vol. 27, no. 8, pp. 1106-1109, 1981.

[19] Y. Sato, S. O. N. Aria, I. Toguchi, T. Fukuda, Y. Ueda, and T. Yoshimoto, "Osseous Choristoma of the tongue: report of a case," Japanese Journal of Oral and Maxillofacial Surgery, vol. 27, no. 1, pp. 93-95, 1981.

[20] A. Esguep, E. Espinoza, and G. Diaz, "Lingual osteoma," Journal of Oral Medicine, vol. 37, no. 1, pp. 27-29, 1982.

[21] M. H. Wasserstein, M. SunderRaj, R. Jain, G. Yamane, and A. P. Chaudhry, "Lingual osseous choristoma," Journal of Oral Medicine, vol. 38, no. 3, pp. 87-89, 1983.

[22] D. M. Main, "Osseous polyp of the tongue: osteoma or choristoma?," British Dental Journal, vol. 156, no. 8, pp. 285-286, 1984.
[23] S. M. Sheridan, "Osseous choristoma: A report of two gases," The British Journal of Oral \& Maxillofacial Surgery, vol. 22, no. 2, pp. 99-102, 1984.

[24] M. Shimono, T. Tsuji, Y. Iguchi et al., "Lingual osseous choristoma: Report of 2 cases," International Journal of Oral Surgery, vol. 13, no. 4, pp. 355-359, 1984.

[25] S. Weitzner, "Osseous choristoma of the tongue," Southern Medical Journal, vol. 79, no. 1, pp. 69-70, 1986.

[26] S. Markaki, J. Gearty, and P. Markakis, "Osteoma of the tongue," The British Journal of Oral \& Maxillofacial Surgery, vol. 25, no. 1, pp. 79-82, 1987.

[27] M. J. Tohill, J. G. Green, and D. M. Cohen, "Intraoral osseous and cartilaginous choristomas: report of three cases and review of the literature," Oral Surgery, Oral Medicine, and Oral Pathology, vol. 63, no. 4, pp. 506-510, 1987.

[28] N. van der Wal and I. van der Waal, "Osteoma or chondroma of the tongue; a clinical and postmortem study," International Journal of Oral and Maxillofacial Surgery, vol. 16, no. 6, pp. 713-717, 1987.

[29] S. C. Cannon and J. K. Niparko, "Pathologic quiz case 1. Lingual osteoma," Archives of Otolaryngology - Head \& Neck Surgery, vol. 114, no. 1, pp. 92-94, 1988.

[30] P. J. Bernard, J. M. A. Shugar, R. Mitnick, P. M. Som, and R. Meyer, "Lingual osteoma," Archives of Otolaryngology Head \& Neck Surgery, vol. 115, no. 8, pp. 989-990, 1989.

[31] M. Ishikawa, T. Mizukoshi, K. I. Notani, T. Iizuka, A. Amemiya, and H. Fukuda, "Osseous choristoma of the tongue: Report of two cases," Oral Surgery, Oral Medicine, and Oral Pathology, vol. 76, no. 5, pp. 561-563, 1993.

[32] N. Wei Cheong, L. C. Boon, and P. Shanmahasuntharam, "Osseous choristoma of the tongue," The Journal of Nihon University School of Dentistry, vol. 38, no. 1, pp. 49-51, 1996.

[33] A. M. Manganaro, "Lingual osseous choristoma," General Dentistry, vol. 44, no. 5, pp. 430-431, 1996.

[34] C. C. Lin, C. H. Chen, Y. K. Chen, Y. H. Shen, and L. M. Lin, "Osseous choristoma of oral cavity-report of two cases and review of the literature," The Kaohsiung Journal of Medical Sciences, vol. 14, no. 11, pp. 727-733, 1998.

[35] M. Vered, J. P. Lustig, and A. Buchner, "Lingual osteoma: a debatable entity," Journal of Oral and Maxillofacial Surgery, vol. 56, no. 1, pp. 9-13, 1998.

[36] M. H. Benamer and A. M. Elmangoush, "Lingual osseous choristoma case report and review of literature," Libyan Journal of Medicine, vol. 2, no. 1, pp. 46-48, 2007.

[37] M. E. Demirseren and N. E. Aydin, "A lingual osteoid mass originating from hyaline cartilage," Journal of CranioMaxillo-Facial Surgery, vol. 35, no. 2, pp. 132-134, 2007.

[38] D. D. Andressakis, A. G. Pavlakis, E. Chrysomali, and A. Rapidis, "Infected lingual osseous choristoma. Report of a case and review of the literature," Medicina Oral, Patología Oral y Cirugía Bucal, vol. 13, no. 10, pp. E627-E632, 2008.

[39] V. R. Naik, W. A. Wan Faiziah, and M. Y. Musa, "Choristoma of the base of the tongue," Indian Journal of Pathology \& Microbiology, vol. 52, no. 1, pp. 86-87, 2009.

[40] J. Y. Liu and K. K. Tan, "Lingual osteoma: case report and literature review," Singapore Medical Journal, vol. 52, no. 10, pp. e198-e200, 2011.

[41] B. R. Adhikari, J. Sato, T. Morikawa et al., "Osseous choristoma of the tongue: two case reports," Journal of Medical Case Reports, vol. 10, no. 1, p. 59, 2016. 
[42] S. Turan, M. Ö. Pınarbaşlı, M. Açıkalın, E. Kaya, and E. Özüdoğru, "Lingual osseous choristoma," Turkish Archives of Otorhinolaryngology, vol. 54, no. 2, pp. 86-88, 2016.

[43] M. J. Heinz, S. M. Peters, S. M. Caruana, and A. J. Yoon, "Lingual osseous choristoma of the tongue base: unusual presentation of a rare entity," Case Reports in Otolaryngology, vol. 2017, Article ID 3234086, 3 pages, 2017.

[44] N. Leigh, R. Anteby, T. Awan, and C. Sinclair, "Lingual osseous choristoma causing odynophagia in a young female," Ear, Nose, \& Throat Journal, no. article 145561320968928, 2020.

[45] T. Hemmi, J. Suzuki, S. Sato et al., "A case of an incidentally removed lingual osseous choristoma," Case Reports in Otolaryngology, vol. 2020, Article ID 3498915, 4 pages, 2020.

[46] L. E. Church, "Osteoma of the tongue: Report of a case," Oral Surgery, Oral Medicine, and Oral Pathology, vol. 17, no. 6, pp. 768-770, 1964.

[47] A. Busuttil, “An osteoma of the tongue," The Journal of Laryngology and Otology, vol. 91, no. 3, pp. 259-261, 1977.

[48] E. B. Cabbabe, C. Sotelo-Avila, S. T. Moloney, and M. V. Makhlouf, "Osseous choristoma of the tongue," Annals of Plastic Surgery, vol. 16, no. 2, pp. 150-152, 1986.

[49] M. Maqbool, R. Ahmad, and R. Ahmad, "Osteoma of the tongue: a rare cause of upper airway obstruction," Indian Pediatrics, vol. 29, no. 11, pp. 1429-1431, 1992.

[50] G. J. Lutcavage and D. K. Fulbright, "Osteoma of the tongue," Journal of Oral and Maxillofacial Surgery, vol. 51, no. 6, pp. 697-699, 1993.

[51] C. Horn, H. M. Thaker, D. A. Tampakopoulou, L. M. D. Serres, J. L. Keller, and J. Haddad Jr., "Tongue lesions in the pediatric population," Otolaryngology and Head and Neck Surgery, vol. 124, no. 2, pp. 164-169, 2001.

[52] M. Yamamoto, M. Migita, S. Ogane et al., "Osseous choristoma in child with strong vomiting reflex," The Bulletin of Tokyo Dental College, vol. 55, no. 4, pp. 207-215, 2014.

[53] J. K. Stanford 2nd, J. C. Spencer, and J. M. Reed, "Case presentation and images of a lingual osseous choristoma in a pediatric patient," American Journal of Otolaryngology, vol. 36, no. 6, pp. 753-754, 2015.

[54] H. Yoshimura, S. Ohba, Y. Imamura, and K. Sano, "Osseous choristoma of the tongue: a case report with dermoscopic study," Molecular and Clinical Oncology, vol. 8, no. 2, pp. 242-245, 2018.

[55] M. B. Macêdo, S. E. M. Borges, P. . S. Macêdo, and P. . T. M. Borges, "Lingual osteoma as a fortuitous finding on a boy with post-adenoidectomy inflammatory pseudotumor," Oral and Maxillofacial Surgery Cases, vol. 4, no. 3, pp. 115-117, 2018.

[56] D. E. Long and A. W. Koutnik, "Recurrent intraoral osseous choristoma: Report of a case," Oral Surgery, Oral Medicine, and Oral Pathology, vol. 72, no. 3, pp. 337-339, 1991.

[57] M. Dalkiz, R. H. Yurdakul, E. Pakdemirli, and B. Beydemir, "Recurrent osseous choristoma of the masseter muscle: case report," Journal of Oral and Maxillofacial Surgery, vol. 59, no. 7, pp. 836-839, 2001.

[58] A. C. Veni, K. Ashokan, and K. C. Sekar, "Osseous choriostoma of the upper lip," Iranian Journal of Otorhinolaryngology, vol. 32, no. 111, pp. 259-262, 2020.

[59] L. Joffe, J. A. Shields, and J. R. Fitzgerald, "Osseous choristoma of the choroid," Archives of Ophthalmology, vol. 96, no. 10, pp. 1809-1812, 1978. 